\title{
LA HISTORIA EN LA CONCIENCIA AMERICANA
}

\section{Preocupación por la originalidad}

La originalidad; he aquí una de las mayores preocupaciones de la cultura en América. Preguntas sobre la posibilidad de una literatura, una filosofía o una cultura americanas, son el más claro índice de esta preocupación por la originalidad americana. ¿ ¿Originalidad frente a qué? Originalidad frente a Europa, frente a la Cultura Occidental. Sin embargo, la palabra "frente" resulta demasiado fuerte para lo que en realidad se quiere expresar con esta "originalidad". Aunque se use la palabra "frente", más bien debería decirse "ante". Más que enfrentarse, oponerse a Europa o a la Cultura Occidental, lo que se quiere, lo que se busca, es el reconocimiento de éstas. EI reconocimiento, por parte de la Cultura Occidental, de que existen otros pueblos, los pueblos del Continente Americano, que también hacen cultura, que poseen una cultura. Pero no una cultura cualquiera, no una cultura simplemente, sino una Cultura Occidental, una Cultura Europea.

La preocupación por la originalidad de la cultura en América, es así una preocupación que tiene su origen en un afán de reconocimiento: el que puede otorgarle la Cultura Occidental al quehacer americano. La originalidad no es entendida como la creación de algo único, especial, ajeno, irrepetible. No se busca lo distintivo para enfrentarlo a algo; sino para colaborar con algo. Se busca la diversidad, pero en función de un todo del que es parte. Este todo lo forma la Cultura Occidental, de la cual se sabe parte el hombre de América. El americano, al preguntarse sobre la posibilidad de una literatura, filosofía o cultura americanas originales, sólo lo hace en función de lo que la palabra original expresa en su sentimiento más lato: el lugar de origen. Una cultura original por su origen, por el hombre o pueblo que la expresa; pero no por la forma de expresión, ya que ésta deberá ser la propia de la cultura de la que se sabe parte, de la Cultura Occidental.

Por ello, la pregunta sobre la posibilidad de una Cultura Americana se hará más clara en su intención significativa si se expone en otros términos. La pregunta más bien giraría en torno a las posibilidades o capacidad del hombre americano para participar activamente en la creación o recreación de la Cultura Occidental. El hombre americano se pregunta sobre la posibilidad de participar en la Cultura Occidental en otros términos que no sean

1 Cf. mi libro Dos etapas del pensamiento en Hispanoamérica, El Colegio de Méxicn, México, 1949. José Luis Martínez, La emancipación literaria en México, Antigua Librería Robredo, México, 1955. 
los puramente imitativos. No quiere seguir viviendo, como diría Hegel, a la sombra de la Cultura Occidental, sino participar en ella. Es esta su participación la que debe ser original. Esto es, la participación propia del hombre originado en América; la del hombre que, a partir de unas determinadas circunstancias que le han tocado en suerte, interviene en la elaboración de la cultura que considera como propia, aportando a la misma las experiencias que ha originado su situación concreta. Es la preocupación del hombre que quiere ser algo más que el reflejo o el eco de una cultura; la del hombre que quiere ser parte activa de la misma.

Esta preocupación se hace patente en el nacimiento mismo de la lucha por la emancipación política de América respecto a sus metrópolis en Europa. La separación, la ruptura, no viene a ser sino el resultado de la incapacidad de las metrópolis para reconocer a sus colonias capacidad para participar en una tarea que debería ser común al Imperio. Los emancipadores americanos, ante la incomprensión europea, se ven obligados a romper con las Madres Patrias. La rebeldía no es contra la cultura de que se saben hijos, sino contra el tutelaje que, en nombre de la misma, se quiere imponerles. Rotas las ligas políticas la gran preocupación americana girará en torno a la capacidad de los americanos para reincorporarse a la Cultura Occidental, dentro de otra situación que no sea la de subordinados. Independizados políticamente, aspiran a participar como pueblos concretos en la elaboración de la Cultura Occidental. Ahora bien, ¿cómo es que se puede participar en esa cultura en otra forma que no sea la de subordinado, reflejo o eco de la misma? Siendo originales, se contestan. ${ }^{2}$

La originalidad; he aquí el rasgo característico de la Cultura Europea, señalan nuestros emancipadores culturales en América. La originalidad es el único rasgo que debe ser imitado por América. América debe imitar a Europa en esa su capacidad para ser original. Esto es, en su capacidad para enfrentarse a su propia realidad, para cobrar conciencia de sus problemas y buscar las soluciones adecuadas. Es esta capacidad del hombre europeo la que ha originado la Cultura Europea. ${ }^{3}$ Esto es lo que le ha faltado al americano, que se ha empeñado en repetir, en copiar servilmente, los frutos de la Cultura Europea, en lugar de copiar el espíritu que los ha originado. Y la imitación de esta originalidad no puede ser vista, en modo alguno, como ruptura con la cultura en la cual se aspira a participar. "No es esto renegar de los progresos de la ciencia europea -decía José Vic-

2 En este sentido se orientan las respuestas de los emancipadores mentales de la América Hispana, como Sarmiento, Lastarria, Bilbao, etc. Cf. mi libro ya citado.

3 El maestro de Bolívar, Simón Rodríguez, decía: Hispanoamérica "debe ser original" en el sentido en que lo era Europa. Bolívar no era ni más ni menos importante que Washington y Napoleón, cada uno en su ambiente y de acuerdo con sus originales metas. 
torino Lastarria-, ni pretender borrarlos para comenzar de nuevo esa penosa y larga carrera que la inteligencia ha hecho en el Viejo Mundo para llegar a colocarse donde está." 4 No; de lo que se trata es de adaptar ese mismo espíritu que ha hecho posible la ciencia en Europa y que ha de hacerla en América. Una ciencia que, al igual que el espíritu de originalidad europeo, habrá de ser común a la América y a Europa, esto es, al Mundo Occidental del que ambos son parte. “¿Estaremos condenados todavía a repetir servilmente las lecciones de la ciencia europea - preguntaba Andrés Bello-, sin atrevernos a discutirlas, a ilustrarlas con aplicaciones locales, a darles una estampa de nacionalidad?" Si así lo hiciéramos, contesta, traicionaríamos el espíritu de esa misma ciencia, "que nos prescribe el examen, la observación atenta y prolija, la discusión libre, la convicción concienzuda". ${ }^{5}$ Es más, lo que Europa espera de América no es la imitación servil que no aporta nada, sino la colaboración que sólo se puede ofrecer si el americano aplica a su realidad el mismo espíritu que en Europa ha aplicado el europeo y que ha dado origen a la llamada Cultura Occidental. “¡Jóvenes chilenos! -dice Bello-. Aprended a juzgar por vosotros mismos; aspirad a la independencia de pensamiento. Bebed en las fuentes; a lo menos en los raudales más cercanos a ellas... Interrogad a cada civilización en sus obras; pedid a cada historiador sus garantías. Esa es la primera filosofía que debemos aprender de Europa." 6

Sólo en esta forma, considera el americano, América podrá participar en la elaboración de la Cultura Occidental como un igual entre iguales. Sólo imitando su espíritu de originalidad e independencia, y no los puros frutos de ese espíritu, es como América podrá ser algo más que una sombra, un eco o un reflejo de Europa, esto es, una colonia del Viejo Mundo. Hasta ahora los americanos no habían hecho otra cosa que copiar servilmente los frutos del espíritu de originalidad e independencia europeos, en lugar de adaptar ese espíritu para crear sus propios frutos; frutos que serían, a su vez, una aportación a la cultura que es o debe ser común a europeos y americanos. Ahora bien, el reconocimiento de la capacidad del hombre americano para colaborar en la elaboración de la cultura de que es parte, sólo se le habrá de otorgar si demuestra a Europa que posee su espíritu, ese espíritu de originalidad e independencia. Sólo entonces, y no antes, Europa aceptará o solicitará la colaboración de América. Sin la adopción de ese espíritu, América no podrá ser sino una colonia, la fuente proveedora de materias primas que la ciencia europea, aplicando su espíritu, transforma en instrumentos para la felicidad de sus hombres. "Nuestra civilización - dice Bello- será también juzgada

4 José Victorino Lastarria, Discurso pronunciado en la Sociedad Literaria, Santiago de Chile, 1842.

5 Discurso en el aniversario de la humanidad, Santiago de Chile, 1848.

- Autonomía cultural de América, Santiago de Chile, 1848. 
por sus obras; y si se la ve copiar servilmente a la europea, aun en lo que ésta no tiene de aplicable, ¿cuál será el juicio que formará de nosotros un Michelet, un Guizot? Dirán: la América no ha sacudido aún sus cadenas; se arrastra sobre nuestras huellas con los ojos vendados; no respira en sus obras un pensamiento propio, nada original, nada característico: remeda las formas de nuestra filosofía y no se apropia de su espíritu. Su civilización es una planta exótica que no ha chupado todavía sus jugos a la tierra que la sostiene." 7

Lo que aquí se dice sobre la cultura en general, es válido también para aspectos particulares de la cultura, como lo pueden ser los políticos. Ideas como la de independencia y soberanía nacionales tendrán su origen en las ideas que con ese sentido han esgrimido los pueblos occidentales en sus relaciones con otros pueblos. Los grandes próceres de la emancipación política, mental y cultural de la América enarbolarán frente al Mundo Occidental el espíritu de independencia que éste ha hecho patente frente al mundo. Es este espíritu el que importa asimilar y no sus frutos. Estos, los frutos, se darán por añadidura si se asimila su espíritu. En la América de origen sajón, por razones que ofreceré más adelante, la asimilación de este espíritu y, por ende, la inmediata incorporación al Mundo Occidental, será fácil, casi natural; nc. así en la América de origen Ibero, que tropezará con obstáculos internos, provenientes de su propia formación cultural, y con los obstáculos que le pondrá el mismo Mundo Occidental que le sirve de modelo.

Así, la tarea principal, necesaria, para la incorporación de los pueblos americanos al Mundo Occidental, estriba en la asimilación del espíritu de este mundo que se hace patente en las ideas de originalidad, independencia y soberanía individual o nacional. Lo otro, los frutos de este espíritu en el campo cultural, social o político, se darán por sí solos, como expresión de ese espíritu. Sin embargo, no todos los americanos lo entienden así, siendo muchos los que se empeñan en imitar, copiar, los frutos de ese espíritu occiàental. Imitación extralógica que acabará fracasando ante una realidad para la cual esos frutos no han sido creados. Imitación que se hará patente en la adopción de sistemas políticos, constituciones, legislaciones, orden social, estilos artísticos, sistemas filosóficos, etc., etc. La resistencia de la realidad americana a someterse a formas que no tienen su origen en ese espíritu de criginalidad e independencia, será vista bajo signos negativos, con los signos de inferioridad con que el Mundo Occidental ha caracterizado a los pueblos primitivos, razas inferiores o naturalezas inmaduras. Primitivismo, inferioridad, inmadurez, serán los calificativos que se darán a sí mismos, a su cultura y a su tierra, estos americanos empeñados en ser una réplica de Europa, del Mundo Occidental; empeñados en imitar los frutos de ese Mundo

7 Bello, op. cit. 
y no en asimilar su espíritu. Es en estos americanos en los que se hará patente la idea de estar fuera de la Cultura, fuera de la Historia, fuera de lo humano. Para estos hombres lo importante son los frutos y no el espíritu que los ha creado. Por ello, fuera de los frutos creados por el europeo u occidental, no hay cultura, ni historia, ni humanidad. Partiendo de este punto de vista, América no puede ser otra cosa que expresión de la barbarie, los confines de la cultura; y sus hombres, si son nativos, serán bárbaros, salvajes, primitivos, y si son originarios de Europa, desterrados, expulsados de la cultura, la historia y la humanidad.

\section{América al margen de la Historia}

La idea de encontrarse al margen de la Historia, entendiendo por tal la Historia Europea o Historia del Mundo Occidental, se hace patente tanto en los pueblos americanos de origen sajón, como en los de origen latino. Sin embargo, es en los segundos en los que esta idea adquiere mayor fuerza y perfiles casi trágicos. Las razones, causas u orígenes de esta actitud, son los que trataremos de hacer patentes a lo largo de este trabajo. Los primeros adoptaron fácilmente el espíritu que había hecho posible la Cultura Occidental, lo cual les permitió crear nuevos frutos y asimilar muchos de los que se habían creado en Europa. En los segundos, la dificultad empezó con la asimilación de ese espíritu, lo cual, a su vez, les impidió asimilar plenamente los frutos de ese espíritu de la Cultura Europea. La América Sajona no sólo asimiló el espíritu de la Cultura Occidental, sino se convirtió, a su vez, en el natural desarrollo de la misma. La América Latina no; ésta se encontró a la larga con el hecho de que la adopción de ese espíritu implicaba la renuncia a otro; la renuncia a un modo de ser con el cual no se conjugaba el espíritu llamado occidental. Y es que el latino planteó el problema de la asimilación del espíritu occidental en relación con sus frutos. Asimilar este espíritu implicaba, para el latinoamericano, asimilar sus frutos tal y como éstos se habían dado en Europa o Norteamérica; frutos que a su vez representaban, en muchos aspectos, las antípodas de la cultura en que él había sido formado. Pertenecía también a la Cultura Europea, pero a una etapa de la cultura que había sido puesta en crisis para dar origen a otra nueva expresión de ella, a la llamada Cultura Moderna u Occidental, que surge gracias a la conciencia que cobró de sus relaciones con el Viejo Mundo Oriental al expandirse para conquistar toda la tierra. ${ }^{8} \mathrm{El}$ latinoamericano se sabía formado en la Cultura Europea Cristiana que había sido puesta en crisis por la Modernidad. España y Portugal, la misma Francia, habían resistido la ofensiva

8 Esta cultura, a la que también se le da el nombre genérico de Modernidad, representa algo así como el polo opuesto de la Cristiandad que le antecede, y da origen a las llamadas instituciones liberales y a la industrialización mediante la técnica. 
de este nuevo mundo; habían resistido y combatido sus ideas. España -colonizadora de la mayor extensión de América, así como su descubridora y conquistadora-, había sido en Europa el paladín del mundo puesto en crisis. El triunfo de la modernidad en Europa había significado también la derrota de la España que se había opuesto a ello. España, y con España, Portugal y el Mundo Latino, habían sido puestos al margen de la nueva expresión de la Cultura, de la Cultura Ilamada Occidental. Esto es, al margen de la Historia, al margen de la nueva expresión de lo humano.

Por ello, para el latinoamericano, reincorporarse a la Historia significaba asimilar, no sólo el espíritu que había hecho posible el Mundo Moderno u Occidental, sino también sus frutos. $\mathrm{Y}$ para asimilar este nuevo espíritu y estos frutos era menester, a su vez, renunciar al propio espíritu y a los frutos de este espíritu heredado de España y Portugal. No faltaron, como veremos más adelante, hombres en esta América Ibera que mostrasen cómo la adopción de ese espíritu era compatible con el espíritu heredado y con los frutos del mismo; que lo que era incompatible era la implantación de los frutos de la Cultura Occidental a la realidad iberoamericana sin su previa adaptación a la misma. ${ }^{\circ}$ Sin embargo, habría de predominar la idea de que lo importante era imponer en esta América las instituciones y expresiones de la Cultura Ocidcental si se quería obtener también el espíritu que las había criginado, aunque esta imposición significase el arrasamiento de la cultura y espíritu heredados. Esta cultura y su espíritu fueron vistos como el mayor obstáculo para la incorporación de la América Ibera a la Historia que estaban haciendo los pueblos modernos. Se realizaba una inversión en la adopción de los instrumentos para incorporar a la América Ibera en esta Historia. Una inversión que a la larga habría de serle fatal, provocando resultados inversos a los que esperaba. Las mentes más claras del Mundo Iberoamericano se empeñaron siempre en que lo importante era adoptar el espíritu de independencia y originalidad que había hecho posible el Mundo Moderno y sus instituciones culturales, sociales y políticas; este espíritu, adaptado a la realidad iberoamericana, daría a la larga sus frutos, como los había dado ya en Europa y los Estados Unidos de Norteamérica. Pero otras mentes más impacientes, menos realistas, encontraron más fácil invertir los términos: adoptar primero los frutos de la Cultura Moderna pensando que con su adopción se obtendría a la larga el espíritu que los había originado. ${ }^{10}$ Estableciendo, por

9 Cf. mi artículo "Catolicismo y Modernismo en la conciencia iberoamericana", Diánoia, 2, Fondo de Cultura Económica, México, 1956.

10 Tal fue, por ejemplo, el espíritu que animó a los educadores hispanoamericanos que, como en México, encontraron en el positivismo un buen instrumento para hacer hombres prácticos semejantes a los sajones y con su mismo sentido para el trabajo personal y las instituciones liberales. Cf. mis libros El positivismo en México, El Colegio de México, México, 1943; Apogeo y decadencia del positivismo en México, México, 1944, y el ya citado libro Dos etapas del pensamiento en Hispanoamérica. 
ejemplo, la Constitución Norteamericana, cualquier pueblo iberoamericano acabaría siendo demócrata y liberal. Decretar la libre competencia, el libre cambio y la libertad de comercio que habían fincado la grandeza económica de los pueblos modernos, bastaría para fincar la de los pueblos de la América Ibera. Sin embargo, la realidad era otra. El establecimiento de esta constitución en los pueblos iberoamericanos no originó democracias, ni el libre cambio hizo la grandeza económica de los mismos. Lo primero sólo dio origen a dictaduras llamadas democráticas y lo segundo subordinó a estos pueblos a economías de pueblos más fuertes y más hábiles en esa lucha que implicaba la libertad de competencia.

La preocupación por establecer en América no sólo el espíritu europeo, sino también sus frutos, era ya vieja en los pueblos iberoamericanos, tenía sus raíces en la misma etapa colonizadora. Y en este aspecto cabe también señalar una diferencia respecto al espíritu que animó a los colonizadores sajones de la América en relación con el que animaba a los iberos, especialmente a los españoles. Los primeros, los sajones, buscan en América la realización de un mundo nuevo que no puede ser realizado en Europa. Se trata de hombres, igualmente nuevos, esto es, sin acomodo en las viejas sociedades europeas de origen feudal. Muchos de estos hombres ven en América la oportunidad de crear el mundo que han soñado para Europa. ${ }^{11}$ Un Mundo Nuevo donde han de tener acomodo sus nuevos ideales. Un mundo en el cual no hay que luchar contra viejos intereses creados. Un mundo virgen que podrá ser moldeado de acuerdo con los ideales de la Modernidad. Así, hombres que se sienten ajenos a los ideales de la vieja Europa cristiana, fuera del orden por ella establecido, se lanzarán a una aventura en la que tienen mucho que ganar y prácticamente nada que perder. Esta aventura la representa la colonización de América. Una tierra virgen a la que se va dominando palmo a palmo de acuerdo con el espíritu de la Modernidad. En esta tierra se va creando el mundo que se ha soñado para Europa. Un mundo que no opone más obstáculos que los naturales, incluyendo en esta naturaleza a sus habitantes, a los indígenas o naturales de esas tierras que no son otra cosa que expresión de esa naturaleza por dominar.

No sucede lo mismo con los conquistadores y colonizadores de las tierras que habrán de formar la América Ibera. Estos, los iberos, lejos de quemar las naves de su pasado como lo hacen los sajones en América, se lanzan a la aventura para crear en el Nuevo Continente un mundo semejante al que dejan en la vieja Europa, en España y Portugal. La única diferencia es que, en este mundo creado por ellos en América, tendrán el acomodo que no tienen en el europeo. Un mundo en el cual se puedan crear lugares de privilegio que ya se encuentran ocupados en Europa. Un mundo en el cual los campesinos puedan ser terratenientes, los siervos señores, los peones caba-

11 Cf. las utopías de Moro, Bacon y Campanella. 
lleros, los villanos nobles. Un mundo semejante al de la Península Ibera, pero con otros señores y otros siervos. Un mundo con nuevas Cortes, castillos, feudos, tierras y súbditos. Un mundo en el cual el antiguo servidor pueda ser amo. Tal es lo que tratarán de establecer los conquistadores y colonizadores de la América Ibera. ${ }^{12}$ No se trata de crear un mundo nuevo, sino de reproducir el antiguo, para buscar en él el acomodo que no se encuentra en el original.

Sin embargo, pese a todos sus esfuerzos, el iberoamericano no puede evitar la permanente comparación de sus creaciones con las del mundo que le sirve de modelo. $\mathrm{Y}$ es en esta ineludible comparación donde surge siempre la decepción. Los nuevos señores, la nueva nobleza americana, no se sienten satisfechos; a pesar de sus esfuerzos, no se sienten semejantes a esos señores que les sirven de modelo. Por mucho que imiten a ese señor en sus hábitos, costumbres, formulismo y ceremonial; a pesar de las exageraciones que realizan para asemejarse o sobrepasar a su modelo, se saben distintos, muy distintos de los hombres que forman la vieja y rancia nobleza peninsular. Todo es en vano, hay algo que impide que se realice en América el mismo mundo que ha sido creado en Europa. La Nueva España nunca será España. Todos los esfuerzos se agotan en una inútil repetición que a la larga resulta caricaturesca. Y es que el iberoamericano, a diferencia del sajón, no intenta crear un mundo nuevo sino repetir aquel del cual es originario.

En estos hombres empieza ya a formarse la idea de que son desterrados de la Historia. América empieza a ser vista como un lugar de destierro. Idea aún más poderosa en los hijos de los conquistadores y los colonizadores: los criollos. Para éstos, el destierro es un destierro no buscado, como en el caso de sus padres. Pagan en América el castigo de una culpa que ellos no han cometido. Son hombres que se encuentran dentro de un mundo que ellos no han elegido, por obra de una ambición que no ha sido la suya. ${ }^{13}$ Criollos y mozambos se empeñan, aunque inútilmente, en recrear el mundo abandonado por sus padres. Hagan lo que hagan, se encontrarán siempre con que se trata de malas copias, malas imitaciones, de un mundo al cual pertenecen y del cual han sido arrojados por culpas que no son las suyas. La ambición, la rebeldía satánica de conquistadores y colonizadores que se negaron a aceptar el lugar que les correspondía en el Viejo Mundo, para crear otro a la altura del mismo, ha dado origen a una culpa que pagan sus hijos y los hijos de sus hijos. Un pecado original que heredan y purgan todos los americanos. ${ }^{14}$ Destierro de la Historia, expulsión del paraíso que

12 Cf. José Durand, La transformación social del conquistador, Porrúa y Obregón, México, 1953.

13 Cf. Fernando Benítez, La vida criolla en el siglo xvi, El Colegio de México, México, 1953.

14 Cf. H. A. Murena, El pecado original de América, Sur, Buenos Aires, 1954. 
representa pertenecer a la Cultura Europa, que se hará sentir en las diversas generaciones culturales que han surgido en la América Ibera desde la Colonia hasta nuestros días. ${ }^{15}$

Sentimiento de culpa que en nuestros días se hace sentir en muevas generaciones de criollos, en pueblos, como la Argentina, en los que la emigración europea a América es aún reciente. Hombres que al igual que los criollos de ayer se resisten aún a formar parte de un mundo que no consideran como propio. "América - dice Murena- es el destierro del recinto de la historia." El americano no es sino un expulsado del ámbito del espíritu. "Porque América es el alma europea expulsada del antiquísimo recinto de la historia, desterrada, contemplando su remoto asilo, embargada por una secreta, incesante pregunta sobre las causas de la presente culpa que motivó el destierro." Y esta culpa, como la de los conquistadores y colonizadores de ayer, lo fue la ambición, la soberbia de los hombres que buscaron, en la aventura del oro y la riqueza, la manera de alcanzar los privilegios que Europa les negaba dentro del orden por ella establecido. Hombres que cambiaron su primogenitura, el hecho de pertenecer a la Cultura y la Historia, por un plato de oro y riquezas que no compensan la pérdida. Es ésta la herencia recibida por los americanos, es éste el pecado de América y de los americanos. El heredero de esta culpa, sigue diciendo Murena, trata inútilmente de escapar a su realidad buscando subterfugios que lo hagan olvidarla. Unos tratan de situarse en el futuro y otros en el pasado, para no tener, en un caso o en otro, que aceptar un presente que no consideran propio. De cualquier manera, dice Murena, "América es un hijo crecido y sin experiencia, un joven senil que vive a la sombra de sus padres, estancado, en cuyos días se alternan los banquetes brutales y silenciosos y las interminables peroratas huecas y eruditas, que simbolizan lo mismo: falta de vida, falta de espíritu".

El criollo de ahora, como el de ayer, se lamenta, no tanto por lo que no posee sino por lo que pudiendo poseer no tiene. Formando parte, como formaba, de la Cultura Europea; siendo, como era, parte de la Historia por excelencia, la Historia Universal que ha hecho y hace el europeo u occidental, la ha dejado, por obra de sus padres, para hacer otra historia. Una historia ajena a la Historia por excelencia, que él, el criollo, no ha pedido hacer y que ahora se ve obligado a realizar. El criollo no quiere empezar la historia como si nada estuviese hecho; simple y puramente quiere formar parte de la Historia que se ha venido haciendo, de la Historia ya hecha por el Espíritu - como señalaba Hegel-, el cual no hace más que tomar conciencia de sí mismo, autorrealizarse, leerse en un libro que ha sido escrito desde la eternidad. Todo lo que esté fuera de este Espíritu no podrá ser más que un remedo de la Historia. "Los americanos - sigue diciendo Murena- somos los

15 Cf. Alfonso Reyes, Oltima Tule, Imprenta Universitaria, México, 1942. 
parias del mundo, como hez de la tierra, somos los más miserables entre los miserables, somos unos desposeídos. Somos unos desposeídos porque lo hemos dejado todo cuando nos venimos de Europa o de Asia, y lo dejamos todo porque dejamos la historia." Los americanos "no tenemos historia, no tenemos padre". Nuestro secreto es pasar "de todo a nada". Destierro absoluto, caída por una culpa que ahora pagan todos. "En un tiempo habitábamos en una tierra fecundada por el espíritu - sigue Murena-, que se llamaba Europa, y de pronto fuimos expulsados de ella, caímos en otra tierra en bruto, vacua de espíritu, a la que dimos en llamar América." "En aquel tiempo estábamos en el campo de lo histórico, y la savia y el viento de la historia nos nutrían y nos exaltaban, hacían que cada objeto que tocábamos, cada palabra que enunciáramos, cada palmo de tierra que pisáramos, todo, tuviese un sentido, fuese una incitación; ahora poblamos naciones situadas fuera del magnífico círculo de lo histórico, naciones a las que la historia sólo alarga la mano en busca de recursos materiales, por lo que la historia tiene para nosotros una significación puramente material, y cada contacto con ella resulta vano y humillante." "De poder ser todo lo que el hombre es, hemos pasado a no poder ser casi ni siquiera hombres. De la semilla sembrada en buena tierra, nos hemos convertido en la semilla que cayó entre espinas." 16

\section{Conciencia de la Historia}

La conciencia del destierro, de apartamiento de la Historia es, como se verá más adelante, una conciencia de la historia que viene a ser el polo opuesto de la conciencia que sobre la misma tiene el hombre moderno en Europa y en Norteamérica. Este tratará, desde su nacimiento, de borrar su relación con una historia que no ha hecho. El iberoamericano no; éste no quiere saber nada de una historia que no sea la del mundo del que se sabe originario, sea ésta cristiana o moderna. El moderno, y con el moderno, el creador de la América Sajona que es su máxima expresión, no quiere saber nada de una historia que no ha hecho. La historia, si ha de existir, tendrá que comenzar con él. No acepta culpas ajenas, no se siente culpable de nada porque nada ha hecho aún. Por ello se sitúa en el terreno de lo ahistórico. Es un inocente, el estado de inocencia es un estado ahistórico. La inocencia no tiene conciencia del pasado, nada tiene que ver con él, es inocente de sus hechos. Consciente de este hecho, el hombre moderno se ha empeñado en presentarse ante el mundo como un inocente, como el hombre que no es culpable de lo hecho por sus antepasados. En realidad no tiene antepasados, la historia comienza con él; él es el inventor de la historia. Camina hacia el futuro sin bagaje alguno, no carga con nada que no sea el producto de su propia acción.

16 H. A. Murena, op. cit. 
El iberoamericano no; éste no sólo quiere cargar con las culpas de la Historia, sino que considera una culpa no cargar con ellas. El conquistador y colonizador iberoamericano viene a la América con un plan distinto al del anglosajón; su misión no es crear un Mundo Nuevo, sino recrear y ampliar el viejo del que es originario. La Historia debe seguir su marcha en América, es el futuro de ella; pero un futuro ligado estrechamente a un presente y a un pasado europeo. Ligado a la Modernidad que es la Europa actual y a la Cristiandad que ha sido la Europa en el pasado. El iberoamericano, y, junto con él, el ibero de la Península y en buena parte el latino, se resiste a amputar cualquier dimensión de la Historia, aunque a la larga, por razones que se expondrán más adelante, acabe realizando, o al menos intente realizar, la más absurda de las amputaciones a diferencia del moderno que, a partir de su presente y en función de su pasado, se enlaza con un pasado que ahora se encuentra ya a su servicio y no a la inversa. El iberoamericano no; éste, obligado por las circunstancias en que se encuentra, al no encontrar la conciliación entre el pasado cristiano que ha heredado y el modernismo que anhela heredar, intenta amputar su pasado para hacerse digno del futuro que anhela. Y, en esta pugna entre su pasado y su futuro, entre lo que es por obra de sus antepesados y lo que quiere ser en el futuro, agota posibilidades que el moderno ha desarrollado sin preocuparse por una amputación que ha aprendido que es imposible realizar.

El iberoamericano, empeñado en hacer de la América otra nueva Europa cristiana, se encuentra con que Europa ha dejado de ser cristiana para seguir nuevos rumbos. El mismo empeño que puso en hacer de América una Europa cristiana, lo pondrá ahora en hacer de la misma una Europa Moderna; en hacer de sus pueblos naciones semejantes a las grandes naciones modernas que van surgiendo en Europa y en la América Sajona. Europa, como ha visto, ha logrado su transformación negando su pasado cristiano. El, el iberoamericano, tendrá que negar también este pasado si ha de ponerse a la altura de los nuevos pueblos directores de la cultura y la civilización. Pero hay algo que no aprende el iberoamericano: la forma de la negación utilizada por el moderno para crear su nuevo mundo. Este, lo mostrarán sus más grandes filósofos de la historia como Hegel, entiende por negar asimilar, conservar la experiencia alcanzada para no tener que volver a repetirla. Pero conservar una experiencia no es mantener su vigencia, salvo en la forma de lo que no tiene por qué volver a experimentar. ${ }^{17}$ Europa ha dejado de ser medieval, feudal, cristiana, para ser moderna; pero no lo ha dejado en forma tal que haya olvidado lo que significa ser tal para poder ser lo que es ahora. En este sentido, el pasado sigue formando parte del presente, y es una función del futuro; pero no lo es en forma tal que signifique un estorbo, un impedi-

17 Estas ideas de Hegel en relación con América las he desarrollado en mi libro, ya citado, Dos etapas del pensamiento en Hispanoamérica. 
mento, un obstáculo. Todo lo contrario. Es la experiencia que ha permitido el presente y ha de permitir el futuro; es lo que ha sido y lo que por tal razón no tiene por qué seguir siendo en otra forma que ésa de haber sido. El iberoamericano no entenderá la negación en esta forma, como un asimilar, conservar, sino en la forma de un amputar. Aún está tratando de hacer que se asimilen el Mundo Cristiano, que ha traído a la América, y el mundo indígena que ha encontrado, cuando ya se siente obligado a renunciar a esta asimilación, para establecer otra forma de mundo que parece la negación de la que ha heredado y ha encontrado. ${ }^{18}$ Compara su situación con la alcanzada por las naciones modernas, y se encuentra a gran distancia de las mismas. Una distancia que sólo podrá salvar, piensa, si corta las amarras que le atan a un mundo de cultura heredado que ya no es el vigente y a un mundo primitivo con el cual se ha encontrado en América. Cree que basta cortar con este pasado hecho presente, para incorporarse sin más al Mundo Moderno. El hombre que ayer se sentía culpable por no poder realizar en América la plenitud de las formas de cultura cristianas heredadas, se sentirá ahora culpable por no realizar las del Mundo Moderno. De su incapacidad de ayer culpará al mundo primitivo americano contra el cual ha luchado; de su nueva incapacidad culpará también a éste y al hecho de haber heredado una cultura que estaba ya fuera de la historia.

Piensa el iberoamericano que basta renunciar a la barbarie americana y a la herencia ibera para que su doble culpa desaparezca y pueda incorporarse al mundo de la cultura y la historia. Para ello, renuncia a la una y la otra como si nada tuviera que ver con ellas, ni aun en la forma de lo que ha sido; renuncia imposible, porque la una y la otra se harán patentes en la forma de lo que no ha sido aún asimilado. No son aún el pasado, la experiencia ya dada, sino el presente, la experiencia que aún no termina. El iberoamericano quiere, como el hombre moderno, entrar en la historia como un inocente, sin culpa alguna en el pasado, negándose a aceptar las culpas de sus antepasados. Pero, a diferencia del moderno, siente este pasado como una culpa, una culpa heredada, original, pero como culpa al fin. Una culpa que no siente el moderno que ha hecho de la misma algo personal y único. Para éste, para el moderno, el pasado ès una experiencia necesaria, algo por lo cual hay que pasar para llegar a la situación en que se encuentra en el presente; pero no algo que determine, que marque, que señale, como el pecado original marcó a los hijos de Adán, limitando sus posibilidades. No; el pasado para el moderno no es una limitación, sino un punto de partida

18 "México -decía Antonio Caso-, en vez de seguir un proceso dialéctico uniforme y graduado, ha procedido acumulativamente." "Aún no resolvemos el problema que nos legó la Conquista, ni tampoco la cuestión de la democracia y ya está sobre el tapete de la discusión histórica el socialismo en su forma más aguda y apremiante." Estas ideas pueden ser también válidas para todos los iberoamericanos. Cf. A. Caso, México (Apuntamientos de cultura patria), Imprenta Universitaria, México, 1943. 
para un futuro cuya ampliación depende de la capacidad del hombre para su logro. El moderno no carga con las culpas de sus antepasados, sino sólo con sus experiencias; las utiliza, las pone a su servicio, le dicen lo que tiene que hacer para que no cometa errores, pero nada más. El futuro es su obra, su obra personal y única, la obra de la sociedad de la que forma parte. El moderno, como se dijo antes, se niega a aceptar como si fuera suyo un pasado que no ha hecho; pero sí lo acepta en la forma de lo que le ha permitido llegar a ser lo que es, a partir de lo cual puede llegar a ser otra cosa. En cambio, el iberoamericano, a pesar de todos los esfuerzos que realiza, siente que no puede liberarse del pasado. Sus antepasados, sus muertos, siguen aún vivos e imponiéndole condiciones, limitando sus posibilidades, haciéndole cargar con sus culpas. No puede ser un inocente, a la manera del moderno; no puede empezar su propia historia; se ve obligado a cargar con la heredada, al mismo tiempo que suspira por no poder cargar con otra que tampoco ha hecho, con la moderna.

Para el moderno, el pasado es algo útil; para el iberoamericano, es un obstáculo. El primero pone el acento en el presente que aprovecha las experiencias del pasado y del cual ha de surgir un futuro cada vez mejor. El iberoamericano no; éste pone el acento en el futuro, en lo que quiere llegar a ser, al mismo tiempo que hace de su presente un campo de permanente lucha contra un pasado que considera como obstáculo para ese futuro anhelado. Por ello uno, el moderno, liga los tiempos de su historia en un armonioso tejido que va progresando en la construcción de lo que se considera un mundo cada vez más perfecto. El otro, el iberoamericano, no; éste estab]ece un corte entre lo que es y lo que ha sido frente a lo que quiere llegar a ser. El primero afirma, en un presente siempre activo, lo que es, como consecuencia de lo que ha sido y como base para lo que puede llegar a ser. El segundo no; éste niega su presente como resultado de un haber sido que no acepta como propio, en función de un futuro que no puede llegar a ser. Uno hace del pasado y del presente la base de todas sus posibilidades; el otro los convierte en el obstáculo que impide su realización. Por ello, para e! moderno, el presente es la realización cotidiana del futuro, una realización natural, lógica, que se va apoyando en los escalones que representa lo realizado, esto es, el pasado. En el iberoamericano esto no es posible, porque ha hecho de su presente la imposibilidad de su futuro $y$, por ende, ha hecho del futuro una simple utopía, esto es, algo inexistente, sin lugar, sin topos. Algo que sólo el milagro podría realizar. Se puede decir que el iberoamericano es un milenarista; un hombre que espera la llegada mesiánica de un futuro que no cree merecer por lo que es y por lo que ha sido. Adán culpable, en recriminación permanente, que espera la llegada de la gracia que ha de situarle entre los elegidos de la Historia, de la Historia de la que se sabe parte vergonzante, de la Historia del Mundo Occidental. 


\section{América como utopía}

La conciencia de la historia propia del iberoamericano tiene, como es de suponerse, su raíz en una realidad que le es propia y original en relación con la de los pueblos en los que se ha expresado la Modernidad. Una realidad que, al ser comparada con la de esos pueblos, ha sido marcada con signo negativo. Signo que la misma Modernidad ha aportado al enjuiciar a pueblos mediante signos culturales distintos de los que la caracterizan. El Mundo Occidental, al expandirse sobre el resto del Mundo, ha creado sus propias interpretaciones de la historia que no son otra cosa más que interpretaciones de su propia historia en relación con la de otros pueblos, aun cuando éstos, como los latinos en general o los iberos en particular, hayan formado parte de su propia historia. Sin embargo, como también veremos con mayor amplitud más adelante, la historia de estos pueblos, la de los latinos o iberos, no será otra cosa más que una parte de la historia que ha negado, que ha asimilado y que no tiene por qué mantener ya en vigencia. La Historia, la verdadera Historia, de acuerdo con este criterio, es la que hace el Mundo Occidental. Los otros, los demás hombres, los demás pueblos, han hecho la Historia, pero no la hacen ya; la pueden llegar a hacer, pero aún no la hacen. Los grandes pueblos asiáticos, la India, China, etc., son pueblos que han hecho la Historia; pero que no la hacen ya más. Los pueblos primitivos que se encuentran en el África y Oceanía, son pueblos que, acaso, harán en el futuro la Historia; pero que todavía no la hacen. Los únicos pueblos que hacen la historia, apoyados sobre lo hecho y en función de lo que puede hacerse, son los llamados pueblos occidentales. ${ }^{19}$ Los pueblos que se han expandido por todos los ámbitos de la tierra haciendo la única y verdadera Historia, una historia en la cual participaron en el pasado otros pueblos y que acaso cuente con la colaboración de otros en el futuro. Pero lo importante, lo real, es el ahora, el presente; y en el presente sólo se crea la Historia que realiza el Occidente. El pasado es recuerdo, el futuro profecía; lo importante es el presente.

Dentro de esta interpretación de la historia de los filósofos del Mundo Occidental, la América Ibera guarda una especial situación. Situación que no guarda la América Sajona. La América, en general, por sus tierras, por su fauna, flora y habitantes naturales es un mundo semejante al africano. Tierra virgen, llena de potencialidades; el mundo del futuro. Pero un futuro que puede convertirse pronto en presente por obra del hombre occidental que está dispuesto a hacer historia sobre ella. Es un Continente aún inmaduro, pero que puede madurar por obra del occidental. El occidental tiene

19 Hegel en su Filosofía de la Historia deslinda el papel de todos los pueblos en la historia eliminando a los no occidentales por haber ya sido y porque sólo en el futuro podrán ser, como América. 
como misión incorporar estas tierras a la Historia Occidental. ${ }^{20}$ En sus manos está hacer de ese mundo del futuro un mundo del presente. Tal es el sentido de la colonización americana. Este ideal, como lo ven los mismos europeos, está siendo realizado por los hombres que están colonizando la América del Norte. Esta América está entrando a grandes pasos en la Historia; pronto el Mundo Occidental habrá de contar con ella. No sucede lo mismo con la América colonizada por españoles y portugueses. Estos, aunque europeos como los sajones, no son más que los últimos y empecinados defensores de un pasado que no tiene por qué seguir permanentemente.

En Iberoamérica se encuentran, así, el futuro y el pasado. Lo que puede llegar a ser con lo que ha sido. Pero falta la amalgama de un presente que ligue el uno con el otro, como lo ha ligado en Europa y lo liga en la América Sajona. Iberoamérica es, como toda la América, el futuro; pero un futuro que no cuenta con el estímulo del presente, como lo cuenta la otra América y Europa, que están creando el Mundo Moderno. El presente iberoamericano no es sino un permanente afianzarse a un mundo que ya ha sido, a una experiencia que no es menester seguir repitiendo. Un mundo situado entre extremos que no puede ligar. Mundo rico en posibilidades, pero sin apoyo en el presente para poder realizarlas. Un mundo dotado de las más grandes riquezas naturales que han fincado la grandeza de los pueblos occidentales en Europa y América; pero que no pueden fincar la de los adustos colonizadores iberoamericanos que se empeñan en mantener una concepción del mundo y de la vida que niega su importancia. Hombres que se conforman con reptir el fasto y la cortesanía de sus decadentes metrópolis, en lugar de crear nuevas dinastías, nuevas formas de fasto y cortesanía. Hombres que dejan virgen el maravilloso mundo de riqueza y bienestar que está a su alcance. Hombres empeñados en repetir un pasado que ya no existe sino en el recuerdo. Pasado y futuro del mundo iberoamericano, pero sin conjugación. El mundo iberoamericano es, al mismo tiempo, todo lo que puede llegar a ser y todo lo que tiene ya razón de seguir siendo. Mundo del futuro, utopía, en cuanto no tiene asiento en una realidad que lo esté realizando. Forma sin contenido, anhelo sin fuerza que lo impulse a realizarse. Esto es nada, aunque pueda teóricamente serlo todo. Tal es la idea que se forma el hombre occidental del Mundo Iberoamericano que queda, al igual que el resto del Mundo, al margen de su Historia, en espera de que sea incorporado a la misma por la vía de su explotación y dominio, como son o van siendo incorporados los pueblos de culturas que fueron en el pasado la Historia, como la India, China, etc.; o pueblos primitivos, que pueden llegar a ser esa misma Historia, pero que aún no lo son: África, Oceanía, etc. Pueblos

20 Cf. Antonello Gerbi, Viejas polémicas sobre el Nuevo Mundo, Lima, 1946. Aquí se analizan las diversas tesis de los europeos sobre América, entre ellas, las que sostienen la necesidad de que la América se europeíce por obra de los europeos. 
todos, orientales, primitivos e iberoamericanos que por alguna razón u otra están fuera del presente de la Historia, fuera de lo que Hegel denominó lo que "es y debe ser". 21

La América Ibera queda, en esta forma, como materia llena de posibilidades a realizar por manos más hábiles. Materia por aprovechar, como se han aprovechado o aprovechan las posibilidades de otros pueblos tan infortunados como ella por su marginación histórica. Es un mundo del futuro; pero de un futuro que no se podrá realizar si no se incorpora a esa historia de la cual es futuro. Una historia en la que participó; pero en la cual ya no puede participar, porque le falta capacidad para hacer de su participación una experiencia para participar en otra forma. El Mundo Moderno, al igual que el Mundo que forma la América Ibera, ha sido, como ella, feudal y católico, en una etapa de la historia en que era menester ser esto; pero ya no lo sigue siendo sino en la forma de haberlo sido. La América Ibera no; ésta se ha empeñado en participar en la Historia en la forma que representó en el pasado. No ha dejado de ser lo que era para ser otra cosa distinta. Pero tampoco vale su nueva actitud: la del que renuncia a lo que ha sido para poder ser otra cosa; porque esta renuncia, lejos de hacer del pasado una experiencia que le sirva para ser otra ocasa, lo quiere transformar en algo que nunca ha existido. $\mathrm{Y}$ junto con este pasado convertido en nada, su presente está también empeñado en aniquilarse. No le queda sino un futuro; pero un futuro sin posibilidades, porque éstas se han esfumado junto con el pasado y el presente aniquilados. Un futuro vacío, sin contenido, ajeno a la realidad iberoamericana que va renunciando a las realidades que podrían darle un contenido, por considerarlas ajenas a ese futuro. Le ha faltado la asimilación de su propia y concreta historia, la conciencia de una historia que aunque no quiera ha venido haciendo. Le han faltado esa conciencia y esa asimilación de la historia, propias de la occidental, de su modelo. Una historia propia, concreta; tan propia y concreta como la historia de cualquier otro pueblo. Una historia en función de la cual han sido puestas otras en los márgenes de la Historia, y que no son sino los márgenes de una determinada y concreta historia. Por ello, el iberoamericano, como otros pueblos del mundo que se encuentran en su situación, ha caído en la trampa que le ha tendido el Mundo Occidental para justificar su expansión y predominio: hacerlos sufrir la expansión y el predominio de la Historia por excelencia, de la Civilización, la Cultura, la Humanidad.

La falta de conciencia de su propia historia, de esa historia que día a día, noche a noche, van haciendo los hispanoamericanos en su lucha contra el mundo o contra sí mismos. Esa historia que el iberoamericano, al igual que todos los hombres, hace para realizar ciertos fines, ciertos valores, no

21 Cf. Filosofía de la Historia. 
importa la jerarquía de los mismos de acuerdo con las tablas con que se les quiera calificar. Una historia que, en alguna forma, es también Historia occidental por lo que ésta representa en su pasado, su presente y su futuro; pero más aún que Historia occidental historia del hombre sin más; historia del Hombre en unas determinadas y concretas circunstancias que lo hacen distinto a otros, pero no inferior ni superior, salvo en el cuadro de valoraciones que sobre su propio quehacer vaya estableciendo. Es esta falta de conciencia histórica de su propio hacer la que le ha permitido aceptar una situación marginal; pero marginal en función de una historia que no es la suya sino en la forma de haber sido o poder ser; pero no en la de la que está siendo, como un hacer concreto y propio y no como un querer hacer puro y simple. Es esta falta de conciencia histórica la que le impide realizar la Historia que realiza el occidental, que no es otra cosa que conciencia de ella, conciencia de su propio y concreto hacer. Una historia, la Historia del hombre occidental, que no depende de ninguna otra historia que no sea en la forma de lo que fue o de lo que puede llegar a ser; pero nunca de lo que está siendo. Una historia, la del occidental, original y única que en todo momento se siente centro; la Historia por excelencia; nunca margen, fuera de algo que sólo ella puede ser.

A fuerza de querer incorporarse a la Historia Europea, Occidental, el iberoamericano ha olvidado que la mejor forma de incorporararse, no a la Historia Europea u Occidental, sino a la historia sin más, es imitar esa misma Historia en aquel aspecto que varios de los próceres de la emancipación mental de Iberoamérica señalaban: la originalidad. Esto es, la capacidad para hacer de lo propio algo universal, válido para otros hombres en situación semejante a la propia. Conciencia que tuvo desde sus inicios el hombre occidental que no sólo se conformó con hacer válidas sus expresiones concretas para hombres en situación semejante a la suya, sino, inclusive, para hombres cuyas circunstancias podían serle diametralmente opuestas. Conciencia de la Historia occidental que hizo de la situación concreta de ésta la situación válida para todos los hombres que aceptasen su subordinación a ella. Conciencia cuyas consecuencias fueron la subordinación a ella de pueblos que no habían cobrado conciencia de sí mismos, conciencia de su propia historia.

\section{Incorporación de América en la historia}

Sin embargo, como ya señalamos páginas atrás, en la América Ibera se ha tomado también la otra actitud: la de los hombres que cobraron clara conciencia de la historia de esta América. Hombres que captaron el verdadero meollo de la actitud que permitió al Mundo Occidental convertirse en paradigma de la Modernidad. Hombres que hablaron a sus contemporáneos 
de la necesidad de adoptar el espíritu de esa actitud y no tanto sus frutos. Esos hombres, al igual que todos los iberoamericanos, también aspiraron a incorporarse a esa Historia del Mundo Occidental, en razón de lo que contenía de humanidad en su más alto sentido. Aspiraron a que nuestra América fuese también un mundo en el que la dignidad y el decoro humanos fuesen su centro. Un mundo que, al igual que el occidental, se preocupase por dominar la naturaleza para ponerla al servicio del Hombre. Un mundo en el que campease el respeto al individuo y sus expresiones. Un mundo en que la convivencia, sobre la base del respeto mutuo, se hiciese patente en esta América. Una América, como Europa, libre y soberana, sin más limitaciones que las que le impusiese la libertad y soberanía de los otros pueblos. Un mundo dentro del cual ese pasado cultural e histórico propio de los países iberos fuese asimilado para su utilización en el futuro desarrollo del mismo. Un mundo que, sin renunciar a la universalidad que implica participar en una tarea que debe ser común a todos los pueblos, mantuviese su individualidad, la originalidad de sus expresiones. Originalidad que sería a la vez una aportación en las tareas que viene realizando la humanidad en común, cobre o no conciencia de ella.

Estos hombres de ayer, como muchos de ahora, se preocuparon por establecer en esta América los valores más altos que había aportado el Mundo Occidental a la Historia del Hombre. Buscaron su establecimiento, pero sin forzar su realidad. Todo lo contrario; buscando, en primer lugar, su conjugación con ella. Modernos, sí; pero sin renunciar a la herencia recibida. Herencia que no era sino acumulación de experiencias vividas para que no fuese necesario volver a vivirlas. Católicos o cristianos, también, pero sin renunciar a! futuro en el que se hace la capacidad del hombre para aprender, esto es, para progresar, para ser cada vez más hombre. Esto es lo que había hecho también el hombre occidental, el moderno, que a pesar de poner el acento de su acción en el futuro ha sabido asimilar su pasado. Tal fue el espíritu que animó, tanto en la Península Ibera como en la América creada por los iberos, a los llamados "Erasmistas" y "Cristianos Nuevos", a los partidarios de la Philosophia Christi; igualmente a los "eclécticos" iberos e iberoamericanos en el siglo xvII; a los Bolívar, San Martín e Hidalgo, para realizar la independencia de la América Ibera; a los que en España y en América se enfrentaron a un pasado que se resistía a ser pura y simplemente experiencia. Este mismo espíritu animó en España a los llamados "Krausistas" y a sus discípulos empeñados en incorporar a España a la Historia, sin mengua de que dejara de ser España. Una España "de carne y hueso", como le gustaría decir a Unamuno. El mismo espíritu que animó y anima en Iberoamérica a los que buscan la conciliación entre el mundo heredado y el que se quiere alcanzar. Todos ellos son espíritus que anhelan para su mundo el mismo bienestar 
material y la misma libertad que los occidentales anhelan y procuran lograr para sus pueblos.

Tal es, también, lo que en este otro sentido se quiere expresar cuando se habla de incorporar a la América a la Historia. Esto es, a una historia que ahora marcha por esos carriles de dignidad individual y "confort" material que no tienen por qué no ser los carriles, las vías, de todos los pueblos. Esa dignidad individual y "confort" material que reclaman para sí los pueblos de origen occidental, los pueblos modernos, no tienen por qué no ser también propios de otros pueblos. No tiene por qué haber pueblos fuera de la Historia o al margen de la Historia a los que se pueda negar el derecho a alcanzar o realizar la una y el otro. El hecho de que haya sido el Mundo Occidental el que ha cobrado, posiblemente, por vez primera, conciencia de los mismos, no implica que ha de ser él el único mundo con capacidad para disfrutarlos. Pues este mundo, al reclamar para sí el respeto a tales derechos, ha hecho, también, conscientes de los mismos a otros pueblos. Una conciencia que, desde su aparición en la historia, la ha tenido el iberoamericano; conciencia que también encontraba su apoyo en aquellos valores, aparentemente desquiciados por la Modernidad, que le permitieron, a su vez, tener una conciencia más amplia de la dignidad, la individualidad y la libertad humanas. Conciencia que en el moderno se fue transformando en un individualismo egoísta que acabó por hacer de su propio individualismo el centro de la historia, la meta, no sólo de sus esfuerzos, sino de los esfuerzos de otros hombres y otros pueblos. Individualismo que acabó haciendo de su yo, un yo deshumanizado, el eje de la historia, el principio y fin de ella; la meta de todo quehacer. Ese Espíritu Objetivo de que nos habló el idealismo romántico y que originó la justificación moral de todas las agresiones, de todos los despojos y de todos los sufrimientos a que se sometió a otros hombres, a otros pueblos que no podían ser, para ese Yo transformado en Espíritu, Civilización o Progreso, otra cosa más que instrumentos para su desarrollo, pasto de su insaciable apetito.

Será, también, este individualismo en que culminó el Mundo Moderno, el que origine la más violenta de las oposiciones a la incorporación del Mundo a ese mundo en el que se hablaba de dignidad humana y felicidad material del individuo. Los hombres y pueblos que hablaban de esta dignidad y felicidad para sí mismos, serán los primeros en oponerse a su realización en otros hombres, en otros pueblos. Y serán los primeros en oponerse, porque tal realización implica la reducción de sus ventajas materiales y, con ello, la negación de una teoría por ellos inventada: la del progreso, entendido éste como infinita acumulación de bienes materiales para el provecho de un individuo o un selecto grupo de individuos. Individuo o grupo de individuos privilegiados a los cuales se encontrará una justificación moral que los haga ser aceptados como tales por todos, aun por aquellos individuos o pueblos 
que pertenecían al grupo de los no privilegiados, de los que colaboraban con su esfuerzo y sus bienes en el bienestar de éstos. ${ }^{22}$

Este individualismo será el que se oponga a la incorporación de otros pueblos, en otra forma que no sea la de subordinación, a la historia que ellos construyen. Asia, África y la América Latina serán excluídas de los ámbitos de la Modernidad con diversos pretextos. En América, esta exclusión tomará aspectos patéticos, ya que los pueblos excluídos de la nueva historia se sabían con derecho a formar parte de ella, dado su origen europeo. Sin embargo, no eran los únicos pueblos de origen europeo los excluídos. En la misma Europa se excluía a otros pueblos, como España. La cual, si bien había representado una de las más brillantes etapas de la Cultura Europea, de la Historia Universal, ya no la representaba; su obra pertenecía al pasado, a un pasado que no tenía ya que repetirse. A ese mismo pasado pertenecían las colonias españolas y portuguesas en América. Los pueblos que surgían de ellas llevaban la mancha del pecado de pertenecer a una etapa de la historia que ya había sido.

Frente a este rechazo los pueblos iberoamericanos se revolverán contra sí mismos buscando en ellos, en su formación, en su herencia, la causa del rechazo. Ya he anticipado los esfuerzos que se realizarán en estos pueblos. para romper con un pasado que consideraban estorboso. Estos pueblos, para escapar a su pasado, a un pasado que no se resignaba a serlo, tendrán que hacer violencia contra sí mismos; pero al mismo tiempo tendrán que luchar contra la resistencia que a su incorporación a la marcha de la Historia oponen los mismos pueblos que les sirven de modelo, los pueblos que representan la vanguardia de esa historia. Por ello, la historia de la cultura iberoamericana es una historia en la que sus hombres realizan una permanente quema de naves, una renuncia permanente a lo que son, para el logro de lo que no sólo no tienen, sino que se evita lleguen a tener. Una historia en la que se alternala admiración por los grandes pueblos que le sirven de modelo con la amarga queja de la actitud de estos pueblos frente a sus admiradores. Hombres que para llevar a sus pueblos las instituciones democráticas y liberales que enarbolan las naciones modernas como signo de superioridad, tienen que luchar, no sólo contra las resistencias que les impone su propia realidad, su pasado aún vivo, sino también contra esos pueblos que se niegan a reconocerles toda capacidad para mantener esas instituciones. Hombres que por establecer en sus pueblos las formas de libertad de las que se presentan garantes pueblos como Inglaterra, Francia o los Estados Unidos, se ven obligados a luchar, no sólo contra los grupos más conservadores de sus propios países, sino contra esos mismos pueblos que admiran y les sirven de modelo, los cuales se han transformado en fuerza que no sólo estimula a las negadoras de sus

22 Cf. mi trabajo "El puritanismo en la conciencia norteamericana", Diánoia, 1, Fondo de Cultura Económica, México, 1955. 
anhelos, sino que inclusive las defiende, enviando en su apoyo todos los elementos materiales que son necesarios para su conservación y triunfo. Tratando de ser modernos, las fuerzas de la Modernidad se pondrán al lado de las viejas y aparentemente fenecidas fuerzas feudales para evitar su logro. ¿Por qué es así y no como esperaban estos hombres? El porqué de esta actitud lo lleva la misma Modernidad en sus entrañas. Es el porqué de la razón por la cual la misma ha dado origen a una Cultura como la Occidental, capaz de expandirse por todo el mundo, como nunca cultura alguna lo había logrado antes. De este porqué y de su impacto en América; de los esfuerzos realizados por ésta para incorporarse a ese mundo moderno que así hacía sentir su pujanza, hablaremos en otro trabajo.

LEOPOLDO ZEA 